\title{
NECK SWELLINGS;
}

STATISTICAL ANALYSIS OF NECK SWELLINGS, PRESENTATION AND DIAGNOSIS AT ALLAMA IQBAL MEMORIAL TEACHING HOSPITAL, SIALKOT.

1. MBBS, FCPS

Associate Professor

Department of Surgery

Allama lqbal Memorial Teaching

Hospital, Sialkot.

2. MBBS

House Surgeon

Department of Surgery

Allama lqbal Memorial Teaching

Hospital, Sialkot.

3. MBBS

Registrar

Department of Surgery

Allama Iqbal Memorial Teaching

Hospital, Sialkot.

Correspondence Address:

Dr. Ansar Latif

House No. 221, Askari Colony 2,

Sector B, Sialkot Cant.

ansarlatif2013@gmail.com

Article received on:

25/06/2018

Accepted for publication:

15/11/2018

Received after proof reading:

26/03/2019
Ansar Latif ${ }^{1}$, Aimen Humayun ${ }^{2}$, Ahsan Jamil ${ }^{3}$

ABSTRACT... Objectives: To collect data of the patients presenting with swellings in the neck, its presentations and final diagnosis. Study Design: Epidemiological Prospective study. Place \& Duration of Study: Department of General Surgery, Khawaja Muhammad Safdar Medical College, Sialkot from January 2015 to March 2018. Patients and Methods: All patients serially presented in the surgery Department of Allama Iqbal Memorial hospital with palpable swellings and lumps in the neck region were registered. The patients were grouped in two categories Group I OPD patients who were not admitted and workup and investigations were carried out in OPD. Group II Admitted patients who required in door admission for investigations, diagnostic and therapeutic surgeries. Results: A total of 1370 patients were included in the study; 1 year to 59 years of age. Out of which 587 were Males and 783 were females (M: $F$ ratio 1:1.15). Out of which 1105 patients were included via OPD GROUP-I; GROUP-II included 215 admitted to ward. Total number of fine needle aspiration cytology carried out were 963. As far as invasive procedures were concerned, total 163 incision biopsies were done out of which 623 were done under local anesthesia and 145 were done under general anesthesia. 18 patients were advised thyroid scan. Patients with posterior triangle neck swellings were 791 which were $71.58 \%$. swellings in oral cavity were 11 making $0.99 \%$ of the total patients in group I. and the aerodigestive tract swellings included 2 patients making $0.18 \%$ of the patients in group I. Whereas in Group II, out of 215 patients, 165 presented with swellings in anterior triangle of the neck making $76.74 \%$ of the total patients in group II. 15 presented with lumps in the posterior triangle of neck contributing $7 \%$ to the total patients in group II. 20 cases were reported with swellings in the oral cavity making $9.3 \%$ of the total and finally 15 patients presented with swellings in aerodigestive tract with a percentage of $7 \%$. Conclusion: Neck swellings and lumps present a challenge to practicing surgeons. It require a tedious workup and investigations to reach a final diagnosis. With all efforts there remains a percentage of patients which remain undiagnosed.

Key words: $\quad$ FNAC (Fine needle aspiration cytology), CT Scan (Computer tomography), UPS (Unknown primary site), MDCT (Multi Detector Computed Tomography).

Article Citation: Latif A, Humayun A, Jamil A. Neck swellings; statistical analysis of neck swellings, presentation and diagnosis at Allama lqbal Memorial Teaching Hospital, Sialkot. Professional Med J 2019; 26(4):646-652.

DOI: 10.29309/TPMJ/2019.26.04.3369

\section{INTRODUCTION}

Neck masses are frequently encountered by surgeons in their clinical practice. They hold a huge magnitude because of the complex anatomy of head and neck region. Not only the anatomy, the physiology of underlying structures make neck region a site of great importance. Due to a vast collection of different structures in the neck there are multiple etiologies for originating neck swellings. Along with that they have different pathologies and prognosis as well. Most common of all are infectious swellings, lymphadenotahies and neoplasias both benign and malignant. The anatomical site of the swellings provides some very beneficial indications regarding the origin and type of swellings. Age is an important parameter to rule out the etiology. Swellings originating after 40 years of age are most likely to be malignant. ${ }^{1}$ As far as the diagnosis is concerned, a proper and detailed clinical examination can help in shaping up a diagnosis. In order to have a firm evidence and surety regarding the type and origin of the swellings, the clinical evaluation of a persistent neck mass may also require imaging studies or biopsy to establish the diagnosis. ${ }^{2}$ 
Imaging techniques form an integral part in the diagnostic workup of neck masses. Out of all the imaging studies Ultrasonography holds a prime importance as a screening test for neck masses.

Due to its non invasive nature and lack of ionizing radiations this is a preferred modality for the initial workup. Ultrasound not only defines the location of the swellings but also provide important information about the internal characteristic of the mass. Along with that it highlights the extent of a mass and its relations with the surrounding structures. But ultrasound lacks specificity in many instances. USG is not always very useful in differentiating between inflammatory and malignant lymphadenopathies. ${ }^{3}$ Although with the advent of Doppler sonography, demonstration of vascular nature of any mass has become more accurate. $^{4}$

Fine-needle aspiration cytology (FNAC) can be performed in patients in whom the physical examination does not explain the neck masses. FNAC is being used as a first line of investigation in the diagnosis of head and neck surgeries. ${ }^{5}$ The technique of FNAC has undergone various modifications over the years. The expansion of FNAC in primary diagnosis of tumors in the last 30 years or so has been impressive and generally successful. FNAC does not give the same architectural detail as histology but it can provide cells from the entire lesion as many passes through the lesion can be made while aspirating period of time. ${ }^{6}$

The development of cross-sectional imaging techniques has substantially altered the management and treatment of the neck masses. Computer Tomography scan (CT scan) is currently the modality of choice in diagnosis of head and neck masses and it is now readily available facility in almost all the health sectors. ${ }^{7} \mathrm{CT}$ is extremely useful in defining both the osseous and soft-tissue extent of the lesion. Besides the plain CT scan, the scans conducted after oral and Intravenous contrasts are considered more significant in adults and also the patients with swellings from and unknown primary. CT with contrast provides adequate information regarding, the size, extent, location, and characteristics of the mass CT scan has a more promising role in defining the relations of any neck mass with the surrounding structures like the great vessels, cranial nerves and other vital structures. ${ }^{8}$

Multi Detector CT scanners have revolutionized the world of diagnosis and management for neck swellings. To permit early recognition of neck pathology, detailed anatomic correlation is mandatory. MDCT provides excellent results in terms of $3 \mathrm{D}$ reconstructions, tissue resolutions and scanning time ${ }^{9}$ The major structures are identified by their appearance and that of the contrasting fatty tissue planes surrounding the soft tissue. Pathologic processes distinguished with MDCT can be either cystic or solid. Most solid masses are mostly lymph nodes.

Over thousands of patients in the clinical settings present with a suspicious lump. The correct knowledge of the primary site is a diagnostic challenge. ${ }^{10}$ Any delay in the diagnosis can lead to deadly results. Neck node metastases from an unknown primary site (UPS) are part of the "Cancer of Unknown Primary" origin, where the primary tumor may remain unknown for a patient's lifetime despite thorough diagnostic work-up. Complete diagnosis can only be made by correct clinical evaluation with apt workup done with imaging studies, radiological studies, and laryngoscopies.

No study regarding neck swellings has been carried in our hospital previously. In the present study, we collected the data of our patients, presentations, investigations and final diagnosis. in patients resenting to general surgery department at Allama lqbal memorial teaching hospital affiliated with Khawaja Muhammad Safdar Medical College, Sialkot.

\section{PATIENTS AND METHODS}

All patients serially presented in the surgery Department of Allama lqbal Memorial hospital with the complain of palpable swellings and lumps in the neck region. The patients were grouped in two categories; Group I OPD patients, which were not admitted in the ward and all the required 
workup and investigations were carried out in opd. Group II Admitted patients, who required in door admissions for investigations and either diagnostic or therapeutic surgeries. Whenever a patient with a suspicious nodule was found, accurate examination of the upper aerodigestive tract mucosa by indirect laryngoscopy and/ or fiber-optic or rigid endoscopy, as well as (bimanual) palpation of the oropharynx and mouth were taken into account as per requirement of every case. If this resulted in the detection of any primary carcinoma, further specific diagnostic measures were taken immediately. Where as if no primary tumor was detected, the next diagnostic step planned was the fine needle aspiration cytology (FNAC) of the node or swelling. The lesions which were more difficult to approach or those for which the cytology was in conclusive, ultrasound guided fine needle aspiration cytology was performed. All ages and both sex patients were included and reviewed. Patients with clear swellings of thyroid i.e. goiters were not included. Along with that the Patients treated and managed by otolaryngologist were also included as those were investigated and diagnosed by the surgical department initially. A minimum three months of follow up was required for inclusion in the study.

Post operative patients, pregnant females and patient who did not not underwent the recommended investigations (Ultrasonography, CT scan, FNAC or biopsy) were excluded from the study. Data was entered and analysis done by SPSS v 22.

\section{RESULTS}

The basic demographic data of our patients is shown in Table-l.

Table-Il shows site of involvement.

Table-III shows presentations

Table-IV shows final diagnosis.

A total of 1370 patients were included in the study; 1 year to 59 years of age. Out of which 587 were Males and 783 were females (M: F ratio 1:1.15). Out of which 1105 patients were included via OPD GROUP-I; GROUP-II included 215 admitted to ward. Total number of fine needle aspiration cytology carried out were 963.

\begin{tabular}{|l|c|}
\hline Total patients registered & 1690 \\
\hline Lost to follow up & 320 \\
\hline Total no of patients in Study & $1370(100 \%)$ \\
\hline Age & $1-59$ years(Mean age 32+5 years) \\
\hline Males & 587 \\
\hline Females & 783 \\
\hline Male: Female & $1: 1.15$ \\
\hline Group I- OPD & 1105 \\
\hline Group II- Admitted & 215 \\
\hline Indirect laryngoscopies by ENT Specialist & 433 \\
\hline Direct laryngoscopies & 215 \\
\hline Bronchoscopies & 72 \\
\hline Upper Gastointestinal endoscopies & 103 \\
\hline Radiographs of Cervical Spine & 600 \\
\hline CT Scans & 181 \\
\hline Fine needle aspiration cytology & 963 \\
\hline Incision biopsies under local anesthesia & 623 \\
\hline Incision biopsies under General anesthesia & 145 \\
\hline Thyroid scan & 18 \\
\hline & Table-l. General data \\
\hline
\end{tabular}




\begin{tabular}{|c|c|c|c|c|c|}
\hline & \multicolumn{2}{|c|}{$\begin{array}{c}\text { Group I- OPD } 1105 \\
(100 \%)\end{array}$} & & \multicolumn{2}{|c|}{$\begin{array}{c}\text { Group II- Admitted } 215 \\
(100 \%)\end{array}$} \\
\hline Anterior triangle of neck & 301 & \multicolumn{2}{|c|}{$(27.23 \%)$} & 165 & $(76.74 \%)$ \\
\hline Posterior triangle of neck & 791 & \multicolumn{2}{|c|}{$(71.58 \%)$} & 15 & $(7.00 \%)$ \\
\hline Oral cavity & 11 & \multicolumn{2}{|c|}{$(0.99 \%)$} & 20 & $(9.3 \%)$ \\
\hline Aerodigestive tract & 2 & \multicolumn{2}{|c|}{$(0.18 \%)$} & 15 & $(7.00 \%)$ \\
\hline \multicolumn{6}{|c|}{ Table-II. Site involved } \\
\hline & \multicolumn{3}{|c|}{$\begin{array}{c}\text { Group I- OPD } 1105 \\
(100 \%)\end{array}$} & \multicolumn{2}{|c|}{$\begin{array}{c}\text { Group II- Admitted } 215 \\
(100 \%)\end{array}$} \\
\hline Fever & 715 & \multicolumn{2}{|c|}{$(64.70 \%)$} & 12 & $(5.60 \%)$ \\
\hline Pain & 632 & \multicolumn{2}{|c|}{$(57.19 \%)$} & 27 & $(12.60 \%)$ \\
\hline Swelling & 1105 & \multicolumn{2}{|c|}{$(100 \%)$} & 215 & $(100 \%)$ \\
\hline Pus Discharge & 35 & \multicolumn{2}{|c|}{$(3.16 \%)$} & 5 & $(2.32 \%)$ \\
\hline Change of voice & 23 & \multicolumn{2}{|c|}{$(2.15 \%)$} & 6 & $(2.81 \%)$ \\
\hline Restricted movements of jaw & - & \multicolumn{2}{|c|}{0} & 3 & $(1.45 \%)$ \\
\hline White patches in the oral cavity & 19 & \multicolumn{2}{|c|}{$(1.71 \%)$} & 26 & $(12.15 \%)$ \\
\hline Red patches in the oral cavity & 8 & \multicolumn{2}{|c|}{$(0.72 \%)$} & 15 & $(7 \%)$ \\
\hline \multicolumn{6}{|c|}{ Table-III. Presentation and management } \\
\hline & & \multicolumn{2}{|c|}{ Group I- OPD 1105 (100\%) } & \multicolumn{2}{|c|}{ Group II- Admitted 215 (100\%) } \\
\hline Bacterial lymphadenitis/ Absces & & 356 & $(32.22 \%)$ & 13 & $(1.17 \%)$ \\
\hline Tuberculous Lymphadenitis/ Ab & & 290 & $(26.24 \%)$ & 27 & $(2.44 \%)$ \\
\hline Lymphoma & & 43 & $(4.00 \%)$ & 21 & $(1.90 \%)$ \\
\hline Parotid tumours/ Pleomorphic a & & - & 0 & 49 & $(4.43 \%)$ \\
\hline Submandibular adenocarcinom & & - & 0 & 8 & $(0.72 \%)$ \\
\hline Lateral Aberrant Thyroid & & - & 0 & 16 & $(1.44 \%)$ \\
\hline Metastatic Squamous cell carcir & & & & 9 & $(0.81 \%)$ \\
\hline Nasopharyngeal carcinoma & & & & 13 & $(1.17 \%)$ \\
\hline Cystic hygroma & & 5 & $(0.45 \%)$ & 7 & $(0.63 \%)$ \\
\hline Cervical rib & & 3 & $(0.27 \%)$ & 2 & $(0.18 \%)$ \\
\hline Sebaceous cysts & & 67 & $(6.11 \%)$ & - & 0 \\
\hline Carcinoma of Tongue & & 9 & $(0.81 \%)$ & 16 & $(1.44 \%)$ \\
\hline Metastatic carcinoma from testic & nours & 2 & $(0.18 \%)$ & 5 & $(0.45 \%)$ \\
\hline Metastasis from Bronchogenic & & - & 0 & 4 & $(0.36 \%)$ \\
\hline Metastasis from Esophageal an & Carcinoma & - & 0 & 8 & $(0.72 \%)$ \\
\hline No final Diagnosis/inconclusive/ & רology & 134 & $(12.12 \%)$ & 17 & $(1.54 \%)$ \\
\hline
\end{tabular}

As far as invasive procedures were concerned, total 163 incision biopsies were done out of which 623 were done under local anesthesia and 145 were done under general anesthesia. 18 patients were advised thyroid scan. Patients with posterior triangle neck swellings were 791 which were $71.58 \%$. swellings in oral cavity were 11 making $0.99 \%$ of the total patients in group I. and the aerodigestive tract swellings included 2 patients making $0.18 \%$ of the patients in group I. Whereas in Group II, out of 215 patients, 165 presented with swellings in anterior triangle of the neck making $76.74 \%$ of the total patients in group II. 15 presented with lumps in the posterior triangle of neck contributing $7 \%$ to the total patients in group II. 20 cases were reported with swellings in the oral cavity making $9.3 \%$ of the total and finally 15 patients presented with swellings in aerodigestive tract with a percentage of $7 \%$. In group I, out of 1105 patients 715 presented with fever making $64.70 \%$ of total patients included in group I. patients presenting will the complain of pain were 632 consisting of $57.19 \%$ of the total. All the patients in group I presented with neck swellings which makes $100 \%$ of patients. 35 patients had pussy discharge which constituted $3.16 \%$ of total 
patients. 23 complained of change in voice along with the complain of swelling making a total of $2.15 \%$. Non amongst group I had restricted movements of jaw. Along with the complain of swelling 19 patients had white patches in the oral cavity, $1.71 \%$ of the total. Few also presented with red patches in the oral cavity consisting of total 8 patients and consisting of $0.72 \%$. In group I, 356 out of 1105 patients (32.22\%) were diagnosed to have Bacterial lymphadenitis/abscess. Whereas in group II, 13 out of $215(1.17 \%)$ patients had bacterial lymphadenitis.

Tuberculous lymphadenitis/abscess was diagnosed in 290 patients (26.2\%) and 27 (2.44\%) patients in group I and II respectively. 43 patients (4.00\%) were diagnosed with Lymphoma in group I while 21 patients (1.90\%) had the same disease in group II. None of the patients in group I had any parotid tumor or pleomorphic adenoma, while 49 patients $(4.43 \%)$ in group were diagnosed as a case of either parotid tumor or pleomorphic adenoma. Similarly no case of submandibular adenocarcinoma was reported in group I, but a total 8 cases $(0.72 \%$ were reported in group II. 16 cases (1.44\%) of Lateral Aberrant Thyroid were diagnosed in group II while none in group I. Metastatic Squamous Cell Carcinoma was diagnosed in 9 patients $(0.81 \%)$ only in group II and no patient was diagnosed to have squamous cel carcinoma in group II. Nasopharyngeal carcinoma was reported in total 13 patient $(1.17 \%)$ in group II whereas none on any patient in group I had this disease. 5 patients $(0.45 \%)$ in group I and 7 patients $(0.63 \%)$ in group II had cystic hygroma. 3 patients $(0.27 \%)$ in group I and 2 patients $(0.18 \%)$ were diagnosed with cervical rib.67 patients $(6.11 \%)$ in group I had sebaceous cysts while none of any patient in group II were diagnosed to have sebaceous cyst. Carcinoma of tongue was diagnosed in 9 patients $(0.81 \%)$ and 5 patients $(0.45 \%)$ in group I and group II respectively. 2 patients $(0.18 \%)$ in group I were diagnosed with swelling in the neck as metastatic carcinoma from testicular tumor while 5 patients $(0.45 \%)$ in group II were reported to have the same cause of swelling in the neck. Metastasis from Bronchogenic carcinoma was reported in 4 patients in group II while no patient in group
I had metastasis from bronchogenic carcinoma as a cause of swelling in the neck region. Cases reported to have metastasis from esophageal and gastric carcinoma were $8(0.72 \%)$ in group II and no such cases were reported in group I. In group I out of 1105 patients 134(12.12\%) were left either undiagnosed or no pathology was detected. Similarly 17 (1.54\%) out of 215 were left undiagnosed in group II.

\section{DISCUSSION}

In our study, bacterial lymphadenitis/Abscess was $25 \%$ in group I \& $11 \%$ in Group II, while in study by Madani et $\mathrm{al}^{11}$, this diagnosis was $33 \%$. The cases of Tuberculous lymphadenitis/abscess were reported to be $290(26.24 \%)$ in group I, and $27(2.44 \%)$ in group II, while according to Perkins et al $^{12}$ total $34.5 \%$ cases were reported to have tuberculous lymphadenitis/abscess.

The final diagnosis of lymphoma diagnosed in the our study were $43(4.00 \%)$ in group I, while 21 $(1.90 \%)$ in group II, where as in study conducted by Boscolo Rizzo et $\mathrm{al}^{13,} 6 \%$ cases were proved to be lymphoma.

There were no cases of Parotid tumors/ Pleomorphic adenoma reported in group I, while 49 cases $(4.43 \%)$ were seen in group II while in study carried out by Tarbiz et $\mathrm{al}^{14} 7 \%$ cases were diagnosed as either parotid tumors or pleomorphic adenoma.

The percentage of patients with submandibular adenocarcinoma in group II was $0.72 \%$ consisting of total 8 patients, while no case was reported in group I, while in a study carried out by Goldenberg. D at el ${ }^{15}$ total $1.75 \%$ patients had submandibuar adenocarcinoma.

16 cases of lateral aberrant thyroid were reported in group II while none in group I which made the total percentage of patients with lateral aberrant thyroid to be $1.44 \%$. while $0.72 \%$ cases were reported in study conducted my Aldridge et al. ${ }^{16}$

Metastatic squamous carcinoma in seen in 9 patients $(0.81 \%)$. cases reported in the study carried out by Bzhalava D et $\mathrm{al}^{17}$ were $2 \%$. 
Total cases of nasopharyngeal carcinoma were 7 in group II while no patient was seen to have this in group I making a total $1.17 \%$. where as total $3 \%$ cases were reported in study done by Horlings H.M et al. ${ }^{18}$

Total 12 cases of cystic hygroma were diagnosed in our study, 5 in group I (0.45\%), 7 in group II $(0.63 \%)$ as compared to the study by Krug. B at el ${ }^{19}$, in which total cases of cystic hygroma were $0.5 \%$.

Cervical rib was diagnosed in 3 patients making $0.27 \%$ of the patients in group I, while in group II total 2 patients were seen to have a cervical rib $(0.18 \%)$, while in the study carried out by Oskam. $\mathrm{M}$ et $\mathrm{al}^{20}$ total incidence of cervical rib was 2 percent.

There were total 2 patients $(0.18 \%)$ in group I and 5 patients $(0.45 \%)$ in group II with metastatic carcinoma from testicular tumors, while in study carried out by Johansen. $\mathrm{J}$ et $\mathrm{al}^{21}$, total incidence of testicular tumor was 3 percent.

Total 4 cases were diagnosed with metastasis from bronchogenic carcinoma in group II while none of any patients in our study had neck swellings due to metastasis from bronchogenic carcinoma in group I. whereas study carried out by Kendirlinan $\mathrm{R}$ et $\mathrm{al}^{22} 8$ cases were reported to have neck swellings secondary to metastasis from bronchogenic carcinoma.

\section{CONCLUSION}

Neck swellings and lumps present a challenge to practicing surgeons. It require a tedious workup and investigations to reach a final diagnosis. With all efforts there remains a percentage of patients which remain undiagnosed.

Copyright(C) 15 Nov, 2018.

\section{REFERENCES}

1. Murata $\mathrm{M}$, Thanan $\mathrm{R}, \mathrm{Ma} \mathrm{N}$ et al. Role of nitrative and oxidative DNA damage in inflammationrelated carcinogenesis. J Biomed Biotechnol 2012; 2012:623019.

2. Chitumalla PK. Study of cervical Iymphadenitis, correlation between clinical features, FNAC and histopathology of cervical lymphadenitis. Int $\mathrm{J}$ Contemporary Med Res. 2016;3(8):2231-4

3. Sudhakar G, Devi KM. Study of ultra sound guided FNAC of liver lesions. International Journal of Contemporary Med Res. 2017; 4(7):1621-3.

4. Gupta G, Joshi DS, Shah A, Gandhi M, Shah NR. FNAC of head and neck swellings. GCSMC J Med Sci. 2014; 3(1):38-41

5. Haynes J, Arnold KR, Aguirre-Oskins C, Chandra S. Evaluation of neck masses in adults. Am Fam Physician. 2015;91(10):698-706

6. Özkan E. A., Göret C. C., Özdemir Z. T., et al. Evaluation of peripheral lymphadenopathy with excisional biopsy: Six-year experience. International Journal of Clinical and Experimental Pathology. 2015

7. Moor J. W., Murray P., Inwood J., Gouldesbrough D., Bem C. Diagnostic biopsy of lymph nodes of the neck, axilla and groin: Rhyme, reason or chance? Annals of the Royal College of Surgeons of England. 2008; 90(3):221-225. doi: 10.1308/003588408x242105.

8. Herrington, C.S. Tumours: Cancer and benign tumours. In Muir's Textbook of Pathology, 15th ed.; Herrington, C.S., Ed.; CRC Press: Boca Raton, FL, USA, 2014; pp. 77-101.

9. Hermans, R. Diffusion-weighted MRI in head and neck cancer. Curr. Opin. Otolaryngol. Head Neck Surg. 2010, 2, 72-78.

10. Chen, X.; Xian, J.; Wang, X.; Wang, Y.; Zhang, Z.; Guo, $\mathrm{J}$; $\mathrm{Li}$, J. Role of periodically rotated overlapping parallel lines with enhanced reconstruction diffusion-weighted imaging in correcting distortion and evaluating head and neck masses using 3 T MRI. Clin. Radiol. 2014.

11. Madani I., Vakaet L., Bonte K., Boterberg T., and De Neve W. 2008. Intensity $\square$ modulated radiotherapy for cervical lymph node metastases from unknown primary cancer. Int. J. Radiat. Oncol. Biol. Phys.71:1158-1166.

12. Perkins S. M., Spencer C. R., Chernock R. D., Haughey B. H., Nussenbaum B., Adkins D. R., et al. 2012. Radiotherapeutic management of cervical lymph node metastases from an unknown primary site. Arch. Otolaryngol. Head Neck Surgery

13. Boscolo $\square$ Rizzo P., Schroeder L., Romeo S., and Pawlita M. 2015. The prevalence of human papillomavirus in squamous cell carcinoma of unknown primary site metastatic to neck lymph nodes: A systematic review. Clin. Exp. Metastasis. 
14. Tabriz HM, Razmpa E, Abdollahi A. Head and neck nerve sheath tumors: A 10-year evaluation in Iran. Iranian Journal of Pathology 2009.

15. Goldenberg,D. ,Begum S., Westra W.H, et al., "Cystic lymph node metastasis in patients with head and neck cancer: An HPV-associated phenomenon," Head and Neck, vol. 30, no. 7, pp. 898-903, 2008.

16. Aldridge $T$, Kusanale A, Colbert $S$, Brennan PA. Supraclavicular metastases from distant primaries: what is the role of the head and neck surgeon? $\mathrm{Br}$ J Oral Maxillofac Surg. 2013; 51:288-293. [PubMed: 22591766].

17. Bzhalava D, Bray F, Storm $H$, et al.: Risk of second cancers after the diagnosis of Merkel cell carcinoma in Scandinavia. Br J Cancer 104 (1): 178-80, 2011.

18. Horlings H.M, van Laar R.K., Kerst J.M, et al., "Gene expression profiling to identify the histogenetic origin of metastatic adenocarcinomas of unknown primary," Journal of Clinical Oncology, vol. 26, no. 27, pp. 4435-4441, 2008.
19. Krug. B, Crott. R, Lonneux. M,. Baurain J.-F, Pirson A.$S$., Vander Borght T, "Role of PET in the initial staging of cutaneous malignant melanoma: Systematic review," Radiology, vol. 249, no. 3, pp. 836-844, 2008.

20. Oskam. M, Hoebers. F, Balm A.J.M, et al., "Neck management in medullary thyroid carcinoma," European Journal of Surgical Oncology, vol. 34, no. 1, pp. 71-76, 2008.

21. Johansen. J, S. Buus, A. Loft, et al., "Prospective study of 18FDG-PET in the detection and management of patients with lymph node metastases to the neck from an unknown primary tumor. Results from the Dahanca-13 study," Head and Neck, vol. 30, no. 4, pp. 471-478, 2008.

22. Kendirlinan R, Ozkan G, Bayram M, et al. Ultrasound guided fine-needle aspiration biopsy of metastases in nonpalpable supraclavicular lymph nodes in lung cancer patients. Multidiscip Respir Med. 2011; 6:220225.

\title{
If you take no risk, you will suffer no defeats. But if you take no risks, you win no victories.
}

\author{
"Richard M. Nixon"
}

\begin{tabular}{|c|c|c|c|}
\hline \multicolumn{4}{|c|}{ AUTHORSHIP AND CONTRIBUTION DECLARATION } \\
\hline Sr. \# & Author-s Full Name & Contribution to the paper & Author $=\mathbf{s}$ Signature \\
\hline 1 & Ansar Latif & $\begin{array}{l}\text { Study design and collected the } \\
\text { data, statistical analysis, proof } \\
\text { reading of manuscript. }\end{array}$ & \\
\hline 2 & Aimen Humayun & $\begin{array}{l}\text { Research on the subject and } \\
\text { statistical analysis, manuscript } \\
\text { writing. }\end{array}$ & \\
\hline 3 & Ahsan Jamil & $\begin{array}{l}\text { Research on the subject and } \\
\text { statistical analysis, manuscript } \\
\text { writing. }\end{array}$ & \\
\hline
\end{tabular}

